\title{
Ultra-fine-Grained Ferrite Prepared from Dynamic Reversal Austenite During Warm Deformation
}

\author{
Hong-Bin $\mathrm{Li}^{1,2,3} \cdot$ Ming-Song Chen ${ }^{2} \cdot$ Ya-Qiang Tian ${ }^{1,3} \cdot$ Lian-Sheng Chen ${ }^{1,3} \cdot$ Li-Qing Chen $^{4}$
}

Received: 14 July 2019 / Revised: 29 September 2019 / Published online: 2 December 2019

(C) The Chinese Society for Metals (CSM) and Springer-Verlag GmbH Germany, part of Springer Nature 2019

\begin{abstract}
The ultra-fine-grained ferrite (UFGF) with the size of less than $1 \mu \mathrm{m}$ is often difficult to be obtained for low-alloyed steel in practical production processing. In this study, considering the rod and wire production process, a new method for preparing the UFGF with submicron scale is proposed by warm deformation of six passes with total strain of 2.6, followed by the cooling process in Gleeble-3500 thermo-mechanical simulator. The results show that the UFGF with an average size of $0.64 \mu \mathrm{m}$ could be obtained via the phase transformation from austenite grains with an average size of $3.4 \mu \mathrm{m}$, which are achieved by the deformation-induced reversal austenization during the high strain rate warm deformation. The main driving force for the reversal transformation is the stress. And the interval between the passes also plays an important role in the reversal austenization.
\end{abstract}

Keywords Ultra-fine-grained ferrite $\cdot$ Dynamic reversal transformation (DRT) $\cdot$ Warm deformation $\cdot$ Deformation-induced reversal transformation $\cdot$ Cooling process

\section{Introduction}

One of the typical features of advanced high-strength steel (AHSS) is the ultra-fine grain which improves the strength and ductility simultaneously [1-3]. In general, the main strategies for grains refinement can be divided into two types [4]: one is the severe plastic deformation (SPD), and the other is the advanced thermo-mechanical process (ATP). The sample size of SPD processing is so small that its application has to face to more limitation than that of ATP. The

Available online at http://link.springer.com/journal/40195.

Ming-Song Chen

chenms18@csu.edu.cn

$\triangle$ Lian-Sheng Chen

07yelian@sina.cn

1 College of Metallurgy and Energy, North China University of Science and Technology, Tangshan 063210, China

2 School of Mechanical and Electrical Engineering, Central South University, Changsha 410083, China

3 Key Laboratory of the Ministry of Education for Modern Metallurgy Technology, Tangshan 063210, China

4 State Key Laboratory of Rolling and Automation, Northeastern University, Shenyang 110819, China
ATP processing includes deformation-induced transformation (DIT) [5], cold rolling and annealing (IA) [6, 7], warm rolling $[8,9]$ and so on. In the hot rolling production, the ferrite grain size is influenced by the size of austenite grains. Generally, the ultra-fine-grained ferrite (UFGF) can be obtained by the phase transformation of very fine austenite. To obtain the UFGF in current hot rolling production, the key is to achieve fine austenite grains in hot rolling processing. There are three main ways to refine the austenite grains: the circle quenching and heating [10], the reversion transformation from the cold-rolled martensite [11-13] and austenite recrystallization or recovery during deformation.

For the former two methods, the martensite is necessary. To obtain the martensite, the cooling rate must be high. And it has to heat the martensite to certain temperature with high heating rate. But in the current hot rolling process, high heating and cooling rates cannot be achieved directly. Thereby, the former two methods cannot be widely applied in the current iron and steel hot rolling processing due to the severe temperature fluctuations. But the third one without the above questions can be used directly.

By the third way, the finest size of austenite grain for $\mathrm{C}-\mathrm{Mn}$ steels is about $10 \mu \mathrm{m}$, and the size of ferrite grains obtained by the method of deformation-induced ferrite transformation (DIFT) is about $1.2 \mu \mathrm{m}$. However, the strength 
will increase substantially if the ferrite grain size is further decreased to less than $1 \mu \mathrm{m}$ from $1.2 \mu \mathrm{m}$, according to Hall-Petch relationship. Chatterjee et al. [14] proposed that the decomposition product would change if the size of parent phase reaches the nanometer. Yao et al. [15] and Sun et al. [16] proposed that the ferrite grain size would achieve the submicron and the cementite would precipitate in the form of particles, if the austenite grain size achieves to 3-4 $\mu \mathrm{m}$. However, it is still a challenge how to obtain the austenite grains with size of 3-4 $\mu \mathrm{m}$ for $\mathrm{C}-\mathrm{Mn}$ steels under the current industrial conditions.

Recently, to obtain fine austenite grains, lots of researches focused on the reversal austenization, which may be an effective way to refine austenite grains. Song et al. [17], Hu and Luo [18] prepared the fine reversal austenite grains during low-temperature annealing. Yang et al. [19] obtained the austenite grains with size of $2 \mu \mathrm{m}$ by heating the cold deformed ferrite. Moreover, for a microalloyed steel, Shen et al. [20] obtained the reversed austenite grain size of $5 \mu \mathrm{m}$, which is only slightly larger than 3-4 $\mu \mathrm{m}$. By analyzing the experimental procedure and results, the reason may be that the relatively low heating rate of reversal austenization goes against the austenite refinement. Inspired by this study, a new method which combines deformation with reversal austenization to obtain fine austenite and further UFGF grain low-alloyed steel was proposed and verified. Moreover, there is a very good application background for this new method. It is well-known that the temperature of specimen increases during the wire/rod finish rolling under the current production conditions due to the plastic deformation [21]. Based on the current industrial production conditions, the DRT will occur due to the increase in temperature and distortion energy caused by the deformation at high strain rate, if the billet enters the finish rolling stage with the microstructure composed of ferrite and pearlite. The fine reversed austenite grains may transform into the UFGF grains with submicron $(0.5-1 \mu \mathrm{m})$ in the followed cooling process.

\section{Experimental Procedures}

The experimental material is a C-Mn steel $(0.46 \mathrm{C}, 0.23 \mathrm{Si}$, $0.72 \mathrm{Mn}, 0.03 \mathrm{P}, 0.03 \mathrm{~S}$, Fe Bal., (wt\%)). The specimen size is $10 \mathrm{~mm} \times 15 \mathrm{~mm} \times 20 \mathrm{~mm}$, and the microstructure consists of ferrite and pearlite with grain size of $\sim 20 \mu \mathrm{m}$. The plane strain tests were conducted in Gleeble-3500 thermo-mechanical simulator. The test scheme is shown in Fig. 1. The multipass strain path is listed in Table 1. The total strain is 2.6 in the multi-pass compression test. To measure the yield stress of austenite at $680^{\circ} \mathrm{C}$, the compression test was carried out based on the test scheme shown in Fig. 1b. The yield stress employed the stress at strain $0.2 \%$. In addition, a single-pass

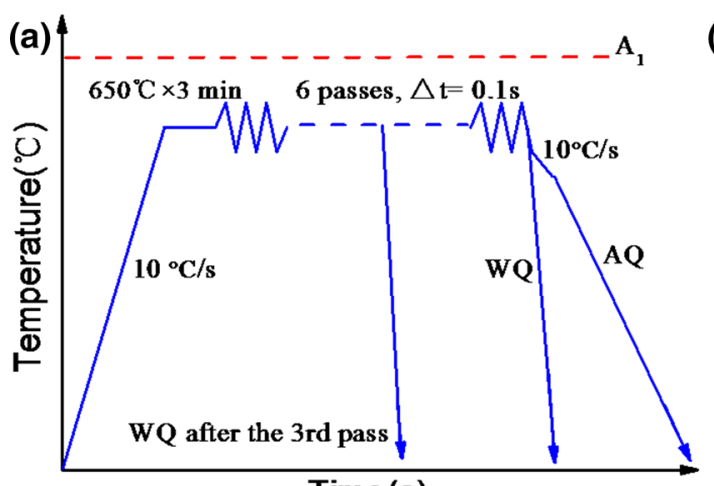

Time(s)

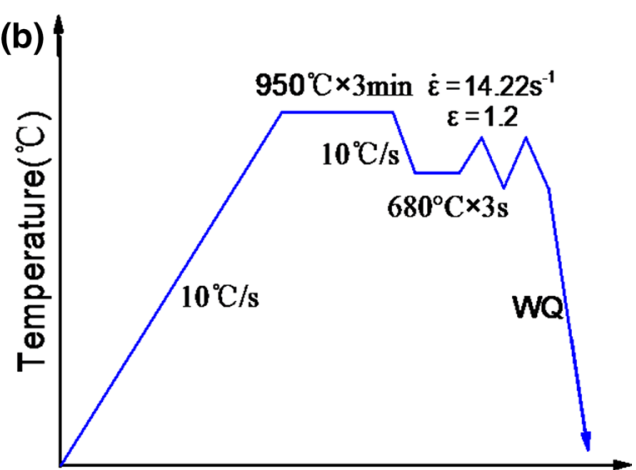

Time(s)

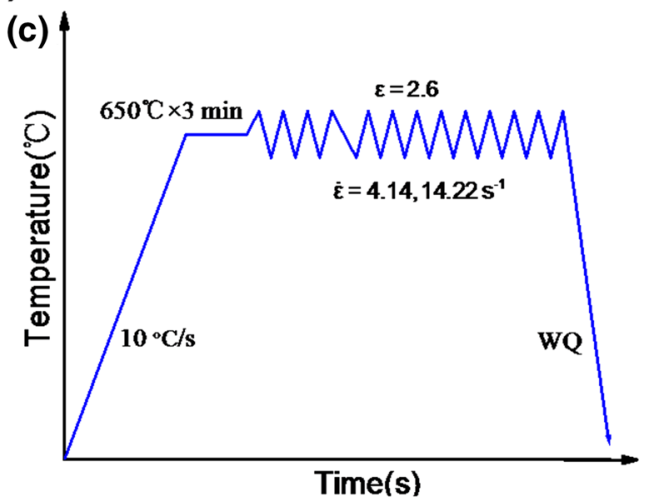

Fig. 1 Test schemes of the experimental steel: multi-pass compression test a, measuring yield stress test $\mathbf{b}$, single compression test $\mathbf{c}$ 
Table 1 Strain path of multi-pass plane strain test

\begin{tabular}{llll}
\hline Pass & True strain & Strain rate $\left(\mathrm{s}^{-1}\right)$ & Interval (s) \\
\hline 1 & 0.39 & 14.22 & 0.1 \\
2 & 0.53 & 17.91 & 0.1 \\
3 & 0.52 & 20.81 & 0.1 \\
4 & 0.49 & 23.54 & 0.1 \\
5 & 0.47 & 27.66 & 0.1 \\
6 & 0.20 & 23.66 & - \\
\hline
\end{tabular}

plane strain test was carried out at $650{ }^{\circ} \mathrm{C}$ (shown in Fig. 1c), and the strain rates are $4.14 \mathrm{~s}^{-1}$ and $14.22 \mathrm{~s}^{-1}$, which are the start strain rate and mean strain rate, respectively. The strain of single pass equals to that of the multi-pass plane strain test.

After compression, the specimen was cooled to $600{ }^{\circ} \mathrm{C}$ with a cooling rate of $10{ }^{\circ} \mathrm{C} / \mathrm{s}$, and then cooled to room temperature in air. The microstructures were observed by scanning electron microscopy (SEM), electron back-scattered diffraction (EBSD) and transmission electron microscopy (TEM). The central part of deformed specimens was observed on SEM after mechanical polishing and erosion in $4 \%$ Nital. The orientation image was analyzed by EBSD with scan step of $0.15 \mu \mathrm{m}$. The samples of EBSD were mechanically and electrolytically polished. The low-angle grain boundaries (LAGBs) are defined between from $2^{\circ}$ to $15^{\circ}$, and high-angle grain boundaries (HAGBs) are above $15^{\circ}$. To avoid the influence of carbides on the statistics of grains size, the preset phases for EBSD test are set as the body-centered cubic (BCC) and face-centered cubic (FCC). TEM samples were cut into $0.5 \mathrm{~mm}$ thickness and mechanically grinded down to about $30 \mu \mathrm{m}$, subsequently thinned to perforation by ion-beam milling. To observe the austenite microstructure, the mixed solution of picric acid, hydrochloric acid erosion and surface action agent test was employed. To observe the original austenite, the etching in solution of picric acid was conducted at $55-75{ }^{\circ} \mathrm{C}$ for $10 \mathrm{~min}$ on the specimen after the third-pass deformation followed by quenching. The austenite grain size was measured by line interception method with an optical microscope (OM).

\section{Results and Discussion}

\subsection{Follow Stress and Temperature}

The deformation can be divided into two stages according to the variation of specimen temperature, as shown in Fig. 2a. In the first stage, most of deformation work transforms into heat, which results in the increase in specimen temperature. Especially during interval, the temperature sharply increases. It is primarily attributed to the annihilation of dislocations, which results in the decrease in distortion energy. A large proportion of decreased distortion energy transforms into heat. Because of the high strain rate, the heat cannot be released into the environment in time. As a result, it causes the sharp increase in specimen temperature during interval.

In the second stage, the peak stresses are relatively stable and less than those in the first stage. It may result from the relatively stable temperature which is in the range of $680-690^{\circ} \mathrm{C}$. The variation of temperature in the second stage is significantly different from that in the first stage. Firstly, in the second stage, the specimen temperature does not increase, even decreases, while it hugely increases in the first stage. Second, the specimen temperature during interval first sharply increases, and then rapidly decreases in the second stage, especially the interval between the third and fourth passes. It indicates that there may be an absorbing heat reaction occurred, which should be reversal austenization. To verify the hypothesis, an interrupt test was conducted. The specimen was quenched immediately after the third pass. After the mixed acid erosion and OM test, the grain boundaries of austenite are shown in Fig. $2 b$. It indicates that the hypothesis is verified. Moreover, the average size of austenite grains is about $3.4 \mu \mathrm{m}$, which achieves the requirement of Refs. [15, 16]. During the followed deformation, the reversal austenization proceeds. The reversal austenization absorbs the heat caused by the deformation. Moreover, there is a rough balance between the heat absorbed by reversal austenization and that generated by deformation. But, the specimen temperature decreases a little at the last pass. It may be ascribed to the small strain of last pass, which cannot offer enough deformation heat to maintain the heat balance. Based on above discussion, it is obvious that the reversal austenization and deformation synchronize during the second stage.

\subsection{Reversal Austenization}

In the second stage, the dynamic reversal austenization (DRT) occurs at the deformation temperature of $680-690^{\circ} \mathrm{C}$, which is obviously lower than $\mathrm{A}_{1}\left(727^{\circ} \mathrm{C}\right)$ calculated according to Ref. [22]. The thermodynamics of DRT can be analyzed by comparing the driving force and obstacle energy. According to the transformation thermodynamics, the driving force is composed of two parts. One can be evaluated as the difference between the flow stress $(\sigma)$ of ferrite up to the critical and the yield stress $\left(\sigma_{\gamma}\right)$ of the fresh austenite [23]. Another is the distortion energy mainly stored in the form of dislocations. According to the results of Ref. [24], the distortion energy only provides small part of the driving force, and it may be neglected. But there is a difference between this research and that reported in Ref. [24]. Therefore, it is necessary to check the proportion of distortion energy in the free energy. The distortion energy 

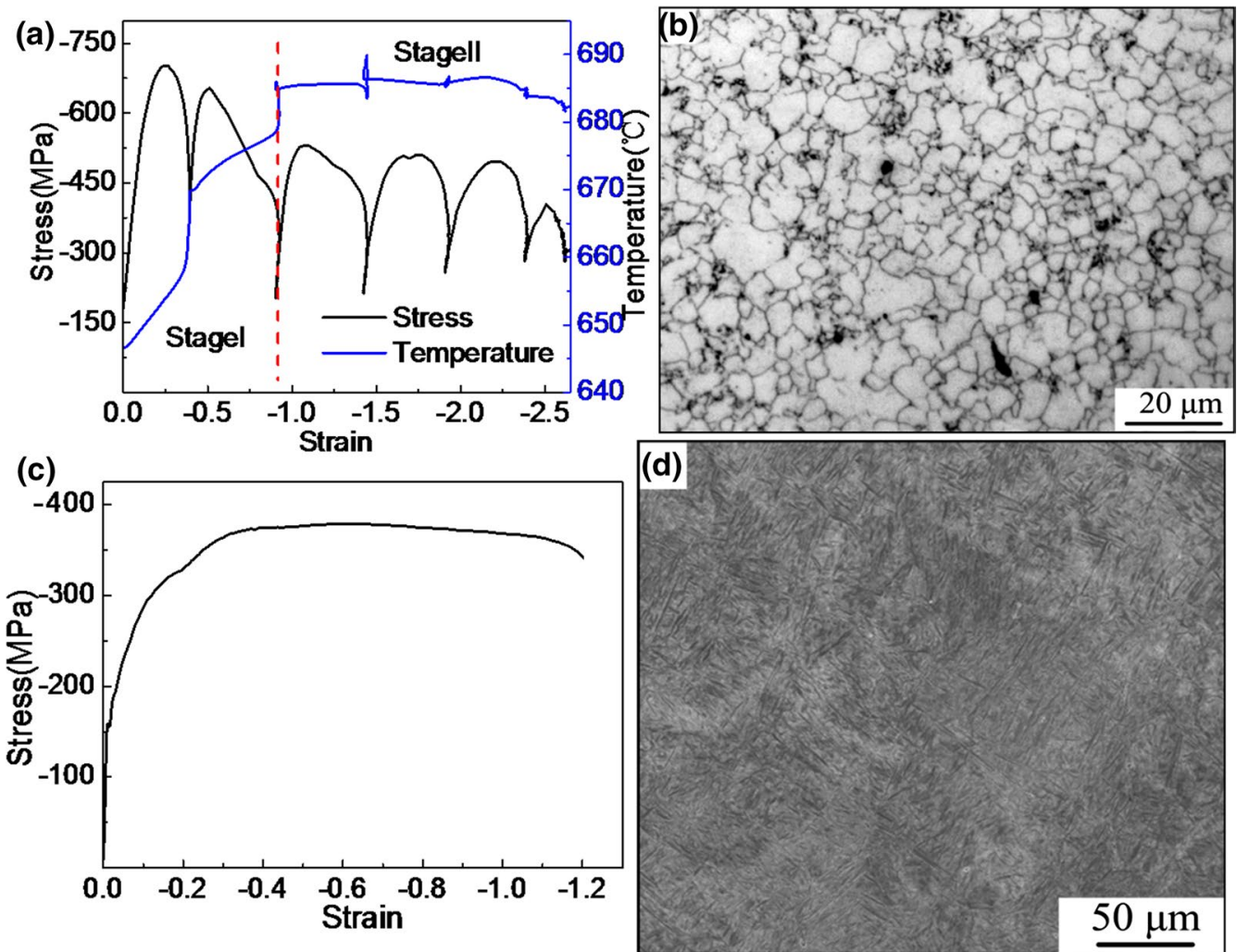

Fig. 2 Flow stress and austenite grains morphology of the experimental steel: temperature and flow stress curves a, reversed austenite $\mathbf{b}$, flow stress of undercooled austenite at $680{ }^{\circ} \mathrm{C} \mathrm{c}$, morphology after the third-pass compression and quenching $\mathbf{d}$

$\Delta G_{\alpha}^{\mathrm{def}}$ facilitates the reversal austenization. The obstacle energy is composed of the free energy $\left(\Delta G_{\alpha-\gamma}\right)$, shear accommodation $\left((W / V)_{\mathrm{SA}}\right)$ and shrinkage work $\left((W / V)_{\mathrm{S}}\right)$ caused by difference of two phases [25]. If the reversal transformation occurs, the difference of ferrite flow stress and austenite yield stress will meet Eq. (1).

$\sigma_{c}-\sigma_{\gamma}=\Delta G_{\alpha-\gamma}+(W / V)_{S A}+(W / V)_{S}-\Delta G_{\alpha}^{\text {def }}$.

Meanwhile, the shear accommodation work and shrinkage work are expressed as Eqs. (2) and (3) [24, 26].

$(W / V)_{\mathrm{SA}}=m \times \sigma_{c} \times 0.36$,

$(W / V)_{\mathrm{S}}=\lambda \times \sigma_{c} \times 0.03$.

Therefore,

$\sigma_{c}=\left(\Delta G_{\alpha-\gamma}+\sigma_{\gamma}\right) /(1+0.36 \mathrm{~m}+0.03 \lambda)$,

$1 \mathrm{MPa}=1 \mathrm{MJ} / \mathrm{m}^{3}=7.2 \mathrm{~J} / \mathrm{mol}$,

$\Delta G_{\alpha}^{\mathrm{def}}=\sigma^{2} / \mu M^{2} \alpha^{2}$, in which $m$ and $\lambda$ is the Schmid and orientation factors $(\lambda=\sqrt{m})$, respectively [23]. $\sigma_{c}$ is the critical stress of austenite DRT. The Schmid factor is 0.5 , which is associated with the maximum resolved shear stress, i.e., with the habit plane of the transformation [24].The value of Schmid factor is decided based on the assumption that the ferrite grains with the highest Schmid factors will transform into the austenite during deformation [23, 27]. $\mu, M$ and $\alpha$ are the shear modulus, Taylor factors, materials constant and the values are $77 \mathrm{GPa}, 2.75$ and 0.24 , respectively [28]. The distortion energy increases with stress. During the second stage, the maximum stress is the peak stress of the third pass, and it is about $532 \mathrm{MPa}$. Therefore, the maximum value of distortion energy is $0.077 \mathrm{~kJ} / \mathrm{mol}$, calculated from Eqs. (5 and 6).

The relationship between the stress and energy can be expressed by Eq. (5). The yield stress (the stress at the strain of $0.2 \%$ ) of austenite at $680{ }^{\circ} \mathrm{C}$ is about $200 \mathrm{MPa}$ according to the flow stress of undercooled austenite, as shown in Fig. 2c. The value of $\Delta G_{\alpha-\gamma}$ is about $0.9 \mathrm{~kJ} / \mathrm{mol}$, calculated by FactSage software. The value of distortion energy is less than one-tenth of the free energy. So, the influence of distortion energy on the transformation can be neglected, which is similar to the results reported in Refs. [25, 29]. Therefore, the value of $\sigma_{c}$ is $265.93 \mathrm{MPa}$, based on Eqs. (4) and (5). It is obvious that the peak stress of multi-pass deformation is 
higher than the critical value. It means that the thermodynamic condition of austenite DRT is achieved. Based on the above results, it is obvious that the calculated critical strain is less than the strain of the first three passes. It may attribute to the induction period and high strain rate. It is well-known that the occurrence of austenite DRT needs the induction period for nucleation. In the period, the compression behavior continued. Due to the high strain rate, it results in that the real critical strain is more than the calculated one.

Another important parameter is the critical strain at which the DRT starts to occur. Based on the critical stress, the critical strain of DRT is evaluated as 0.025 , according to Fig. 2a. But the real critical strain exceeds the calculated one. It may attribute to the immaturity of dynamic transformation condition.

During warm deformation, the lamellar cementite transform into the cementite particles, and the polygonal ferrite grains are compressed into the pancake, which increases the interfaces of among each grain and phase. It increases the interfacial energy and the driving force for reversal austenization. According to the classical nucleation theories, the nucleation rate increases with the increase in nucleation site. Generally, the nucleation sites are composed of the surfaces, edges and corners of grain boundaries with high misorientation. Another important nucleation site is the phase interfaces. Fortunately, the area of grain boundaries and phase interfaces increases with the increase in strain. Therefore, the thermodynamic and dynamics conditions of reversal austenization gradually permit during deformation. At last, the reversal transformation occurs.

Another important condition may be the intervals during the multi-pass deformation. To verify this point, the singlepass compression test was also carried out. The variations of flow stress are shown in Fig. 3a. The flow stress curve at high strain rate exhibits large peak stress. After the peak, the flow stress curves of different strain rates show little difference, which may be ascribed to the large increase in sample temperature at high strain rate, as shown in Fig. 3b. The microstructure of single pass is composed of the ferrite and pearlite, without the martensite, as shown in Fig. 4. It indicates that the austenite DRT does not occur during the single-pass compression.

Based on the comparison of single- and multi-passes compression results, it can be inferred that the influence of intervals on austenite DRT is great. It may attribute to the variation of microstructure during the intervals. During
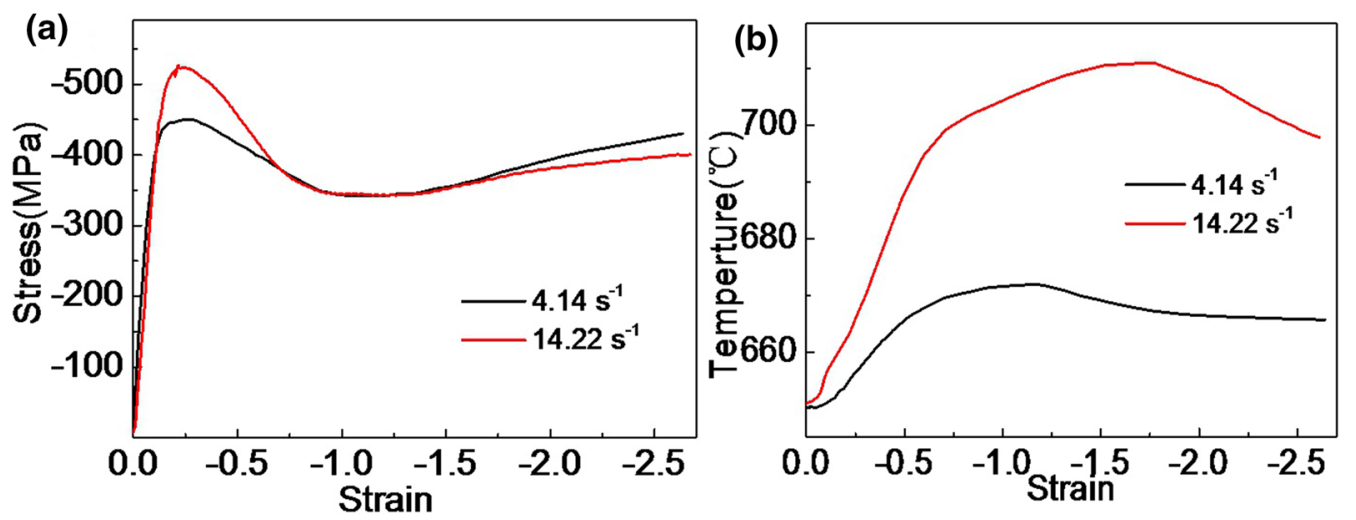

Fig. 3 Variations of flow stress and specimen temperature during deformation at different strain rates: flow stress $\mathbf{a}$, variation of temperature $\mathbf{b}$

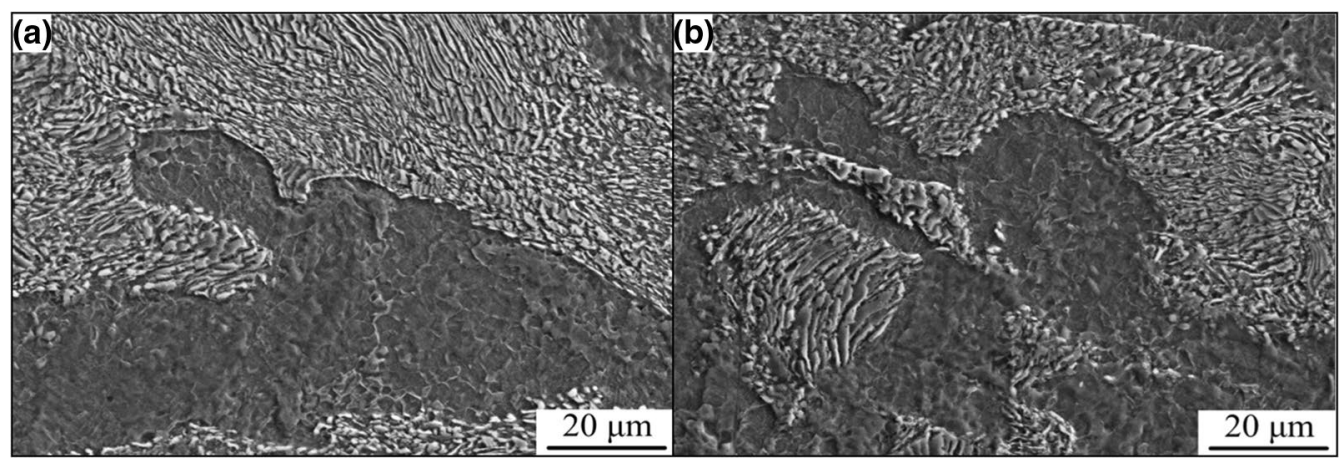

Fig. 4 Microstructures of the experimental steel after single-pass deformation at $650{ }^{\circ} \mathrm{C}$ and different strain rates: $4.14 \mathrm{~s}^{-1} \mathbf{a}, 14.22 \mathrm{~s}^{-1} \mathbf{b}$ 
intervals, the ratio of lamellar cementite decreases and the ratio of cementite particle increases. Meanwhile, in the ferrite grains, the substructure forms by absorbing the dislocations [30, 31]. With the ratio of substructure and cementite particles increasing, both of the microstructure variation results in the increase in the interfaces between phases and grains. The interface is of particularly significance on the phase transformation, grain growth and recrystallization [32-34]. Thus, the possible nucleation sites of reversal austenite increase. It indicates that the carbide particles play a key role in the phase transformation [35].

On the other hand, from a thermodynamic point of view, the driving force of reversal transformation increases with the increase in interface between carbide particles and ferrite. It is obvious that the interface between carbide particles and ferrite is much more than that between lamellar cementite and ferrite. The interface energy of microstructure composed of carbide particles and ferrite is higher than that of microstructure composed of lamellar and ferrite. Therefore, it increases the austenite DRT driving force and facilitates the nucleation of reversal austenite. Meanwhile, the increasing interface energy may decrease the incubation period and critical radius of reversal austenite transformation. It indicates that the intervals may play an important role in the reversal austenite transformation. But the exact mechanism of the intervals action needs to be further researched.

\subsection{Submicron Ferrite Grains Formation}

After the six passes compression, the temperature decreased with the cooling rate $10^{\circ} \mathrm{C} / \mathrm{s}$. And when the temperature decreases to the point $\mathrm{O}$, the current for heating the sample to maintain the temperature variation with the set cooling rate was turned off. The specimen temperature is higher than the set. The reason may be that the cooling capacity of Gleeble cannot meet the requirement or some additional heat sources. But based on the cooling curve, it is obvious that the cooling rate from the points A to B is more than the set, as shown in Fig. 5a. It is well-known that the cooling capacity decreases with the decrease in temperature. Thereby, it can be indicated that the temperature deviation is caused by the additional heat source, not the insufficient cooling capacity. It is obvious that the additional heat source is the latent heat released by phase transformation. So we can preliminary deduce that the start point (point $\mathrm{O}$ ) of deviation is the start temperature of transformation. During the cooling processing from the point $\mathrm{A}$ to $\mathrm{B}$, the cooling rate is more than the set, due to the insufficient of latent heat. Thereby, the point A can be identified as the finish point roughly. Hence, the start and finish temperatures are about 654 and $633^{\circ} \mathrm{C}$, respectively. Often, the ferrite grain coarsening tendency decreases when the temperature is less than $650{ }^{\circ} \mathrm{C}[36$, 37]. Thus, the start transformation temperature of $650^{\circ} \mathrm{C}$ is benefit to the formation of UFGF.

As shown in Fig. 6a, there are lots of carbide particles distributed in ferrite matrix. The carbide particles may be composed of the residual short rod-like cementite and the precipitated carbide particles. Before the reversal austenization, the initial lamellas were broken, distorted and bended during warm deformation [38, 39]. Some cementite lamellas transformed into carbide particles, while the other transformed into the short rod-like. During the reversal austenization, lots of interfaces of carbide particles and ferrite act as the potential nucleation sites, thereby, the nucleation rate increase. When the carbide particles dissolve, the $\mathrm{C}$ atoms dissolve into neighboring regions. It promotes the nucleation and growth of reversal austenite grains [40]. Due to the smaller size, the carbide particles dissolve more rapidly than the rod-like cementite [41]. Therefore, the carbide particles more promote the reversal austenization than the rod-like. If the rod-like cementite decomposition could not complete during the second stage, they were remained in the
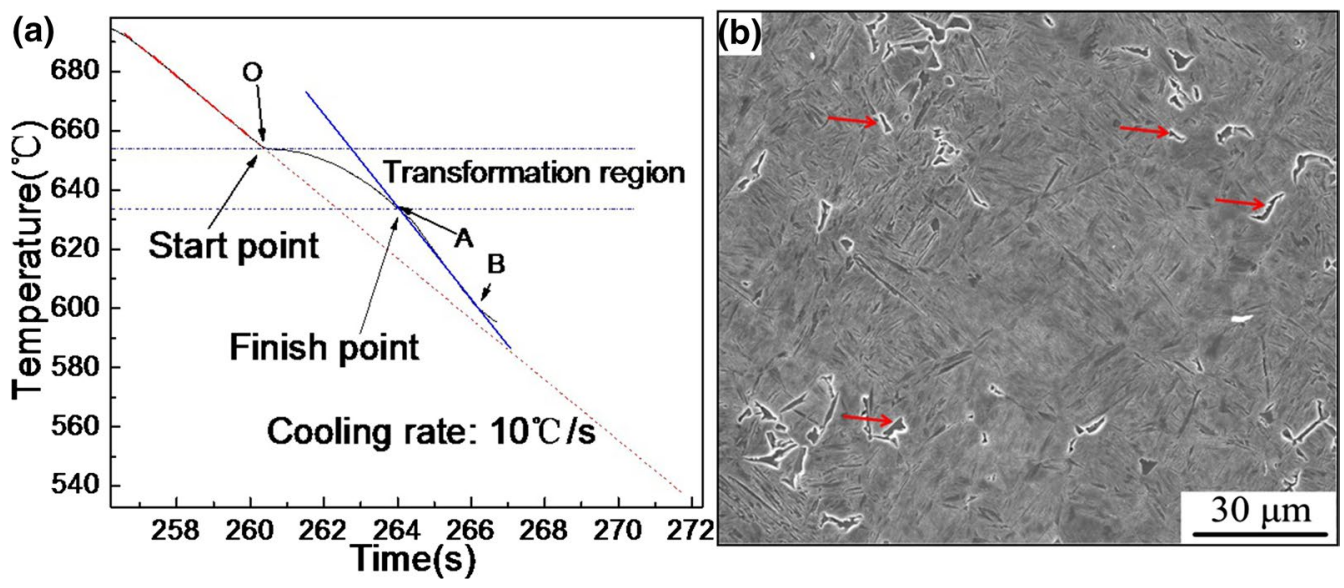

Fig. 5 Cooling curve and quenched morphology of the experimental steel: cooling curve a, quenching morphology after the second stage $\mathbf{b}$ 

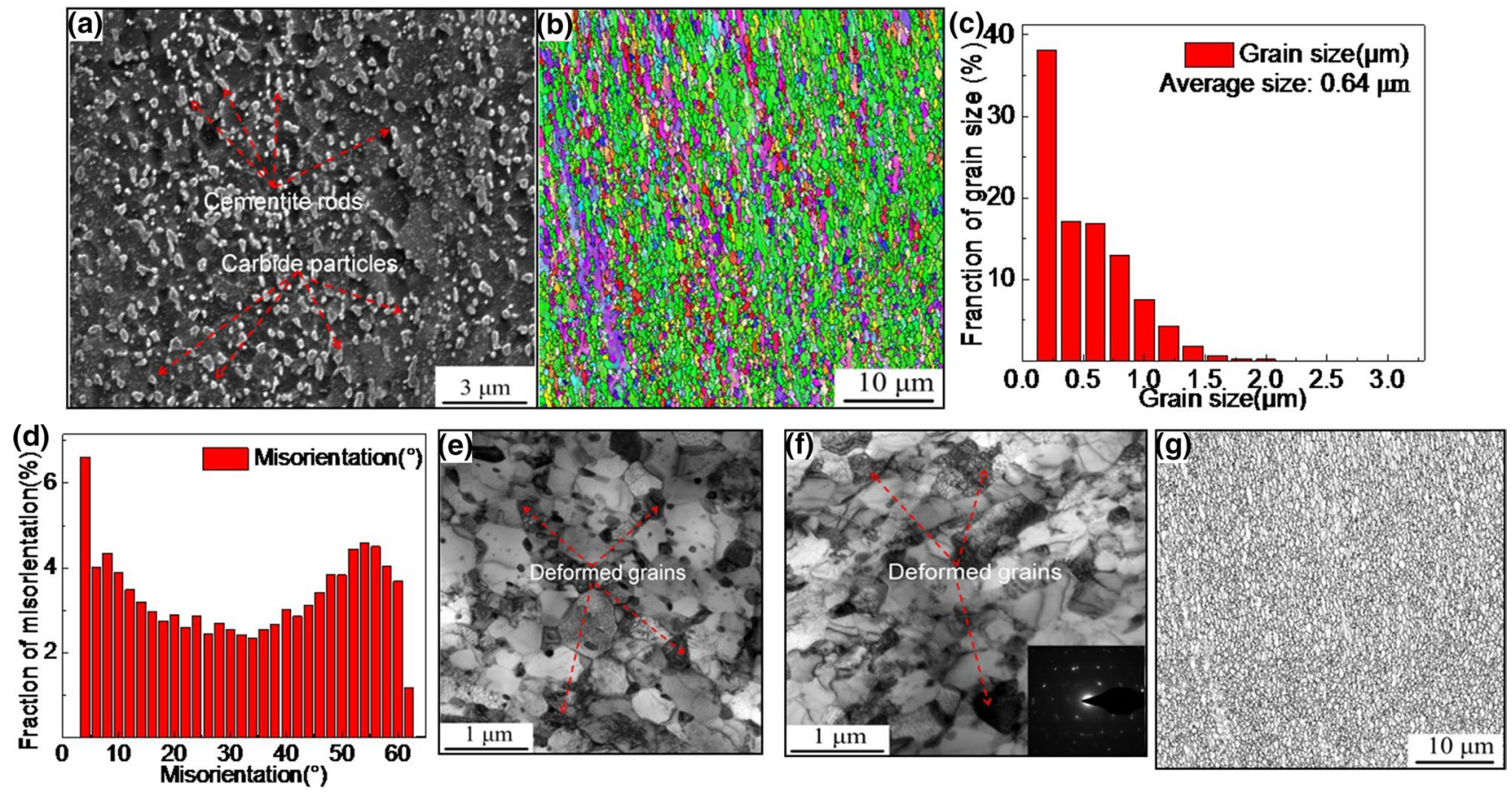

Fig. 6 Morphology of UFGF microstructure: SEM morphology a, orientation map b, grains size distribution (black lines represent HAGBs, while the gray lines denote LAGBs) c, misorientation distribution d, UFGF TEM morphology in initial pearlite e, UFGF TEM morphology in initial ferrite $\mathbf{f}$, grain boundaries map $\mathbf{g}$

fine ferrite matrix after the ferrite transformation. However, the carbon atoms diffused into the reversal austenite matrix precipitated in UFGF matrix during the transformation. At last, the carbide atoms precipitated in the form of carbide particles and short rods [16], as shown in Fig. 6a.

According to Fig. 6b-d, the size of ferrite grains is about $0.64 \mu \mathrm{m}$. In the second stage, the reversed austenite underwent compression and transformed from polygons into pancakes, which increased the length of grain boundaries. Meanwhile, the dislocations inside the deformed reversed austenite grains glided, tangled and aggregated into dislocation walls and substructure boundaries. These boundaries of substructures and fine pancake austenite grains developed into the nucleation sites, and increased the nucleation rate. In addition, the transformation temperature is low. It is well-known that the transformation driving force is affected by the undercooled degree and density of nucleation sites. Thus, the driving force of transformation is large due to the plenty nucleation sites and the low transformation temperature. The large driving force facilitated the nucleation of UFGF grains. In addition, the coarsening of UFGF grains was inhibited due to the low temperature. As a result, the UFGF grains formed under the condition of low temperature and large driving force $[42,43]$.

In the study, the total strain for preparing UFGF grains is about 2.6 , which is relatively small. Generally, the extremely large strain of over 4 or 5 is needed to produce the UFGF grains by the severe plastic deformation. However, the strain of obtaining UFGF grains by advanced thermo-mechanical processing is less than that of SPD. Li et al. [44, 45] fabricated the low-carbon microalloyed steel UFGF grains of 1.1 $\mu \mathrm{m}$ during the critical deformation by the strain of 1.0 with the fine austenite grains. And results of Ref. [45] indicate that the fine austenite grains present is more beneficial to the ferrite refinements than the large grains with deformation bands. Okistu et al. [46] obtained the submicron ferrite grains of $0.49-0.85 \mu \mathrm{m}$ with the strain of 2.8 through cold rolling and annealing of $620-655^{\circ} \mathrm{C}$ for $120 \mathrm{~s}$. Based on the above results [44-46], it is a key to suppress the ferrite grains coarsening for the ultra-fine ferrite grains preparation, it is in accordance with results of Refs. [36, 37]. In this research, the transformation temperature is about $650-630{ }^{\circ} \mathrm{C}$, and it is good for the ferrite grain refinement.

By comparison of the grain size and strain with the results reported by Refs. [34, 35, 42-44], the process proposed by this study has an advantage in respect of ferrite grains refinement with little strain. It may obtain the submicron ferrite within strain about 2.0 through reversal austenization and proper cooling processing. Therefore, it is worth to explore the effect of the second-stage strain on the ferrite grain size and determine the minimum strain for submicron grains formation.

The TEM morphology of UFGF grains on the initial pearlite and ferrite colonies is shown in Fig. 6e, f. The initial 
location of UFGF grains can be roughly distinguished by the density of carbide particles. According to results of Shen et al. [20] and Tsiji et al. [47], the ferrite grain size decreases with the increase in carbon content, due to the particles pinning effect. But, by the comparison of Fig. 6e, $\mathrm{f}$, there is nearly no difference in the grain sizes between the two regions. It may be attributed to the low transformation temperature, which suppresses the ultra-fine ferrite grain coarsening. As shown in Fig. 6f, the select area diffraction pattern is ring-like. It indicates that the various orientations exist.

The boundaries map is shown in Fig. 6g. Most UFGF grain boundaries are HAGs. The deformed grains are not obvious. However, there are some deformed polygonal grains, as shown in Fig. 6e, f. It is thought that the deformed UFGF grains may be formed by the DIFT during the second stage [44]. The microstructure which was obtained by quenching immediately after the second stage is composed of martensite (the appearance of martensite can testify the occurrence of DRT) and a little ferrite, as shown in Fig. $5 b$ (the ferrite is marked by the red arrows). So it can be deduced that there is just a little DIFT occurred during the second stage. It may be attributed to the high strain rate. The research about the effect of strain rate on DIFT showed that the high stain rate went against its occurrence [48]. In the second stage, the strain rate is about $20-27 \mathrm{~s}^{-1}$ and more than the critical values reported in Refs. [49-52]. So the DIFT is inhibited and the fraction of DIFT ferrite grains is little. The stable temperature during the second stage is an additional evidence of the little fraction of DIFT. If there is massive DIFT occurred, the latent heat of phase change would be released during deformation, which would result in an obvious increase in specimen temperature. So the most UFGF grains were transformed from the reversed austenite during the cooling. Based on the above analysis, it can be concluded that the formation mechanism of UFGF grains is composed of DIFT and diffusion transformations from reversed austenite during cooling process, and the last mechanism plays a dominant role.

\section{Conclusions}

(1) The dynamic reversal austenization transformation occurred during the six passes warm deformation with high strain rate, caused by the distortion energy, stress and the increased temperature. The average grain size of the austenite grains is $3.4 \mu \mathrm{m}$.

(2) The intervals between deformation passes play a key role in the formation of the fine grain, which may attribute to that the intervals are in favored of shortening the incubation of austenite formation.
(3) During the cooling, the fine austenite grains transformed into the UFGF grains with the mean size of about $0.64 \mu \mathrm{m}$. The mechanisms of UFGF formation include the DIFT during deformation and subsequent ferrite transformations from reversed austenite with diameter of $3.4 \mu \mathrm{m}$ during cooling. Moreover, the ferrite transformation in cooling process plays a dominant role in the formation of UFGF.

Acknowledgements This work was financially supported by the National Natural Science Foundation of China (Grant Nos. 51574107, 51501056, 51975593), the Natural Science Foundation of Hebei Province (Grant Nos. E2015209243, E2017209048), the Liaoning Provincial Natural Science Foundation of China (Grant No. 2019-KF-25-01), and the Research Funds from Department of Education of Hebei Province (Grant Nos. QN2019051, ZD 2019064).

\section{References}

[1] M.H. Cai, H.S. Huang, J.H. Su, H. Ding, P.D. Hodgson, J. Mater. Sci. Technol. 34, 1428 (2018)

[2] Y. Shao, C.X. Liu, Z.S. Yan, H.J. Li, Y.C. Liu, J. Mater. Sci. Technol. 34, 737 (2018)

[3] D.G. He, Y.C. Lin, J. Chen, D.D. Chen, J. Huang, Y. Tang, M.S. Chen, Mater. Des. 154, 51 (2018)

[4] L.J. Zhao, N. Park, Y.Z. Tian, A. Shibata, N. Tsuji, Adv. Eng. Mater. 1701016, 1 (2018)

[5] X.Y. Hu, H.L. Zhao, S. Ni, M. Song, Mater. Charact. 129, 149 (2017)

[6] H.W. Luo, J. Shi, C. Wang, W.Q. Cao, X.J. Sun, H. Dong, Acta Mater. 59, 4002 (2011)

[7] N. Tsuji, T. Maki, Scr. Mater. 60, 1044 (2009)

[8] M.K. Pathak, A. Joshi, K.K.S. Mer, R. Jayaganthan, Acta Metall. Sin. (Engl. Lett.) 32, 845 (2019)

[9] B. Hu, B.B. He, G.J. Cheng, H.W. Yen, M.X. Huang, H.W. Luo, Acta Mater. 174, 131 (2019)

[10] S.J. Yao, L.X. Du, X.H. Liu, G.D. Wang, J. Mater. Sci. Technol. 25, 81 (2009)

[11] Z. Yanushkevich, A. Belyakov, R. Kaibyshev, C. Haase, D.A. Molodov, Mater. Charact. 112, 180 (2016)

[12] F. Yang, H.W. Luo, C.D. Hu, E.X. Pu, H. Dong, Mater. Sci. Eng. A 685, 115 (2017)

[13] S. Lee, B.C.D. Cooman, Metall. Mater. Trans. A 45, 5009 (2014)

[14] P.P. Chatterjee, S.K. Pabi, I. Manna, J. Appl. Phys. 86, 5912 (1999)

[15] S.J. Yao, L.X. Du, X.H. Liu, G.D. Wang, Acta Metall. Sin. (Engl. Lett.) 21, 391 (2008)

[16] J.J. Sun, T. Jiang, Y.J. Wang, S.W. Guo, Y.N. Liu, Mater. Sci. Eng. A 726, 342 (2018)

[17] Y.Y. Song, X.Y. Li, L.J. Rong, D.H. Ping, F.X. Yin, Y.Y. Li, Mater. Lett. 64, 1411 (2010)

[18] B. Hu, H.W. Luo, Acta Mater. 176, 250 (2019)

[19] G.W. Yang, Z.D. Li, X.J. Sun, X. Yong, Q.L. Yong, J. Iron. Steel Res. Int. 20, 64 (2013)

[20] X.J. Shen, S. Tang, J. Chen, Z.Y. Liu, R.D.K. Misra, G.D. Wang, Mater. Sci. Eng. A 671, 182 (2016)

[21] A.S. Alghamdi, I.A. Ashcroft, M. Song, D.Y. Cai, Poly. Test. 32, 1502 (2013)

[22] J. Trzaska, L.A. Dobrzanski, J. Mater. Proc. Technol. 192-193, 504 (2007) 
[23] C. Aranas Jr., T. Nguyen-Minh, R. Grewal, J.J. Jonas, ISIJ Int. 55, $300(2015)$

[24] J.J. Jonas, C. Ghosh, Acta Mater. 61, 6125 (2013)

[25] C. Aranas Jr., A. Foul, B.Q. Guo, A. Fall, M. Jahazi, J.J. Jonas, Scr. Mater. 133, 83 (2017)

[26] L.J. Zhao, N. Park, Y.Z. Tian, A.S.N. Tsuji, Mater. Res. Lett. 6, $641(2018)$

[27] C. Ghosh, C. Aranas Jr., J.J. Jonas, Prog. Mater. Sci. 82, 151 (2016)

[28] N. Hansen, X. Huang, G. Winther, Mater. Sci. Eng. A 494, 61 (2008)

[29] C. Ouchi, T. Sampei, I. Kozasu, Trans. ISIJ 22, 214 (1982)

[30] H.B. Li, X.P. Zheng, D.C. Wan, L.S. Chen, J. Iron. Steel Res. Int. 26, 602 (2019)

[31] H.P. Li, R. Jiang, L.F. He, H. Yang, C. Wang, C.Z. Zhang, Acta Metall. Sin. (Engl. Lett.) 31, 33 (2018)

[32] H.K. Dong, H. Chen, W. Wang, Y.J. Zhang, G. Miyamoto, T. Furuhara, C. Zhang, Z.G. Yang, S.V.D. Zwaag, Acta Mater. 158, 167 (2018)

[33] C.Y. Zhang, H. Chen, J.N. Zhu, W.B. Liu, G. Liu, C. Zhang, Z.G. Yang, Scr. Mater. 162, 44 (2019)

[34] S.J. Song, W.K. Che, J.B. Zhang, L.K. Huang, S.Y. Duan, F. Liu, J. Mater. Sci. Technol. 35, 1753 (2019)

[35] J.G. Chen, C.X. Liu, W. Chen, Y.C. Liu, H.J. Li, Acta Metall. Sin. (Engl. Lett.) 32, 1151 (2019)

[36] L.H. Hao, N.M. Xiao, C.W. Zheng, D.Z. Li, J. Mater. Sci. Technol. 26, 1107 (2010)

[37] C. Zhang, L. Cui, Y.C. Liu, C.X. Liu, H.J. Li, J. Mater. Sci. Technol. 34, 756 (2018)
[38] C. Prasad, P. Bhuyan, C. Kaithwas, R. Saha, S. Mandal, Mater. Des. 139, 324 (2018)

[39] H. Rastegari, A. Kermanpur, A. Najafizadeh, M.C. Somani, D.A. Porter, E. Ghassemali, A.E.W. Jarfors, Mater. Sci. Eng. A 658, 167 (2016)

[40] G. Miyamoto, H. Usuki, Z.D. Li, T. Furuhara, Acta Mater. 58, $4492(2010)$

[41] H.W. Luo, C.H. Qiu, H. Dong, J. Shi, J. Mater. Sci. Technol. 30, 1367 (2014)

[42] Z.D. Li, Z.G. Yang, C. Zhang, Z.Q. Liu, Mater. Sci. Eng. A 527, 4406 (2010)

[43] B.X. Wang, X.H. Liu, G.D. Wang, Mater. Des. 30, 2198 (2009)

[44] B. Li, Q.Y. Liu, S.J. Jia, Y. Ren, B. Wang, Scr. Mater. 152, 132 (2018)

[45] B. Li, Q.Y. Liu, S.J. Jia, Y. Ren, B. Wang, Acta Metall. Sin. (Engl. Lett.) 31, 1038 (2018)

[46] Y. Okisu, N. Takata, N. Tsuji, Scr. Mater. 60, 76 (2009)

[47] K. Hase, N. Tsuji, Scr. Mater. 65, 404 (2011)

[48] P. Uranga, A.I. Fernandez, B. Lopez, J.M. Rodriguez-Ibabe, Mater. Sci. Eng. A 345, 319 (2003)

[49] L. Cheng, Y.L. Chen, Q.W. Cai, W. Yu, G. Han, E.T. Dong, X. Li, Mater. Sci. Eng. A 68, 117 (2017)

[50] A. Imandoust, A. Zarei-Hanzaki, H.R. Abedi, Scr. Mater. 67, 995 (2012)

[51] X.Z. Chen, Y.M. Huang, J. Alloys Compd. 619, 564 (2015)

[52] P. Gong, E.J. Palmiere, W.M. Rainforth, Acta Mater. 119, 43 (2016) 